\title{
YIELD BEHAVIOUR OF COLD COMPACTED COMPOSITE POWDERS
}

\author{
I. SRIDHAR and N. A. FLECK† \\ Department of Engineering, University of Cambridge, Cambridge CB2 1PZ, UK
}

(Received 15 December 1999; accepted 17 May 2000)

\begin{abstract}
A triaxial test rig is used to study the axisymmetric cold compaction behaviour of powder composites comprising aluminium with silicon carbide reinforcement, and lead shot with steel reinforcement. Under hydrostatic loading the pressure-density response shows an increase in strength with increasing volume fraction of reinforcement. For a given volume fraction of inclusions, the compaction pressure to achieve a given relative density increases with diminishing size of reinforcement. The yield surfaces are measured after isostatic and closed-die compaction; it is found that the shape depends upon the deformation path, with greatest hardening along the loading direction. The effect of reinforcement on the overall shape of the yield surface is found to be minor. (C) 2000 Acta Metallurgica Inc. Published by Elsevier Science Ltd. All rights reserved.
\end{abstract}

Keywords: Powder consolidation; Cold isostatic pressing; Composites; Yield surface; Constitutive models

\section{INTRODUCTION}

Powder compaction is a popular route for the production of light engineering components such as automotive parts. A common production process consists of cold compaction in a closed-die or in an isostatic press followed by sintering. Most of the densification takes place in the cold compaction step by rate-independent plasticity.

Prior to densification, the powder exists in a random state of relative density $D$ (defined by the density of the compact divided by the full density of the solid); $D$ is somewhat less than the dense random packing value of 0.64 . Densification proceeds in two stages as follows. In Stage I, the microstructure can be idealised as discrete particles connected by necks at their contacts. This stage prevails up to a relative density $D$ of about 0.9 . Stage II exists at higher relative densities, and the microstructure comprises a distribution of interconnected or isolated voids.

A number of compaction models for the rateindependent densification of porous materials have been reviewed by Doraivelu et al. [1]. These models assume an elliptical yield surface in deviatoric stress vs mean stress space, and are calibrated against a limited set of experimental data. Doraivelu et al. [1] and Kuhn and Downey [2] calibrated their models

$\dagger$ To whom all correspondence should be addressed. using uniaxial unconstrained compression tests on sintered aluminium alloy. Kim et al. [3] conducted combined tension-torsion tests on sintered iron specimens for the calibration of their yield function. It is important to note that the yield behaviour of compacted and sintered specimens is different from that of cold compacted powders of equal relative density: the cold pressed powder has unbonded inter-particle contacts and a low macroscopic tensile strength, whereas compacted and sintered powder has bonded junctions and a macroscopic tensile strength equal to the compressive strength. Brown and Abou-Chedid [4] compacted iron powder specimens along a range of strain paths to a fixed relative density, and found that the subsequent uniaxial compression response was path dependent, implying the development of anisotropy.

Arzt and co-workers [5-8] have developed micromechanical models for the Stage I isostatic compaction of powders by taking into account the increase in the particle contact number, and the growth of contact area with relative density. These models have been extended by Fleck and co-workers [9, 10] for non-isostatic deformation. Yield surfaces arising from hydrostatic and closed-die compaction are shown in Fig. 1, as taken from Fleck [10]. The yield surfaces are shown for axisymmetric loading, with axes of mean stress and deviatoric stress. Values of stress have been normalised by the macroscopic yield pressure $p_{\mathrm{y}}$ for isostatic compaction [6] 


$$
p_{\mathrm{y}}=3 D^{2}\left(\frac{D-D_{0}}{1-D_{0}}\right) \sigma_{\mathrm{y}}
$$

where $\sigma_{\mathrm{y}}$ is the uniaxial yield strength of the solid material composing the powder particles, and $D_{0}$ and $D$ are the initial and current relative densities of the powder compact. In Fig. $1, \phi$ is a cohesion parameter defined by the ratio of the tensile cohesive strength to the compressive strength at particle contacts; in practice, $\phi$ almost vanishes for cold compacted powders as they have near-zero tensile strength. The yield surface is strongly dependent upon the deformation path, having a vertex at the initial loading point. The path dependence of yielding of copper powder compacts was verified by Akisanya et al. [11]: they found that hydrostatic compaction produces a yield surface which is approximately elliptical in mean stress-deviatoric stress space, whereas closed-die compaction generates a yield surface which is elongated along the loading direction.

Recently, Larsson and co-workers [12] have developed a model of Stage I cold and hot isostatic compaction of monosized powder particles by using

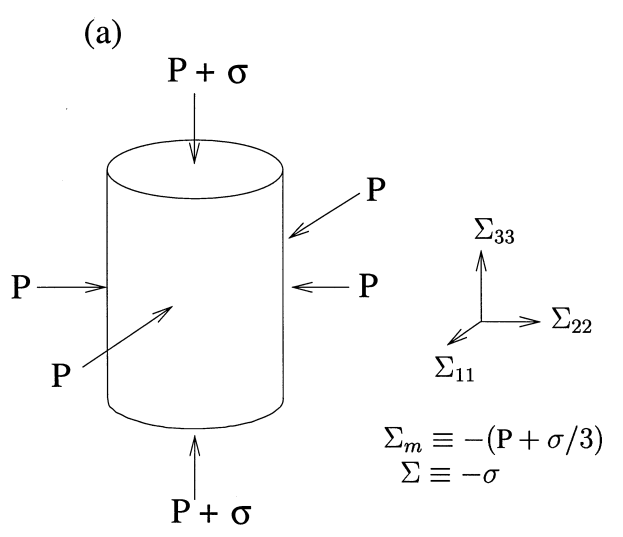

(b)

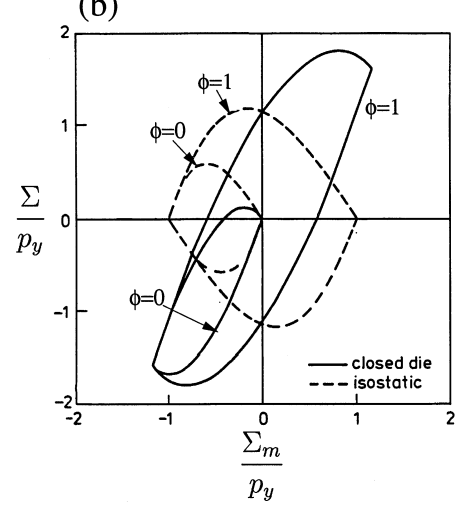

Fig. 1. (a) Axisymmetric loading of powder specimen. (b) Predicted effect of strain path on the evolution of the yield surface [10]. $\phi$ is the ratio of the tensile cohesive strength to the compressive strength at the particle contact, and $p_{y}$ is the hydrostatic yield strength of the compact as given by equation (1). the self-similarity solution obtained for the ball indentation of power-law rigid-plastic and creeping solids. The theoretical predictions are in reasonable agreement with published experimental measurements for the Stage I compaction of copper, tin, bitumen and lead.

Relatively few experimental and theoretical studies have focused on the cold compaction of composite powders. Lange et al. [13] have studied experimentally the cold uniaxial compaction of composite powders consisting of soft metallic particles (lead shot and aluminium) and elastic inclusions (steel). Densification was hindered significantly at inclusion volume fractions of $20 \%$ and higher, and for a given volume fraction, densification was most difficult for those powders with the smallest inclusion size relative to the deformable particles. Turner [14] has carried out a combined experimental and theoretical study on the cold isostatic pressing of composite powders consisting of modelling clay (plasticine spheres) and various volume fractions, sizes and shapes of elastic inclusions made from glass and plastic beads. Composites with a high volume fraction of inclusions, small relative inclusion size, and large inclusion aspect ratio required the greatest pressures to densify. The strengthening arises because the matrix is plastically constrained by the elastic inclusions, and the elastic inclusions shield the plastic matrix powder from densification.

Recently, Storakers et al. [15] have developed a Stage I model to predict the macroscopic compaction response of a powder composite. We begin by summarising the relevant results of their theory.

\subsection{Pertinent results of the powder compaction model by Storakers, Fleck and McMeeking}

Storakers, Fleck and McMeeking (SFM) [15] consider the viscoplastic densification of a composite powder aggregate. Here, we specialise their results to the rate independent case, for equi-sized spherical powder of particle radius $R_{1}$. The underlying uniaxial true stress $\sigma$ vs logarithmic strain $\epsilon$ response is assumed to have the form $\sigma=\sigma_{1} \epsilon^{M}$, where the pre-exponent $\sigma_{1}$ is a strength parameter and $M$ is the strain-hardening exponent. According to their theory, the pressure $P$ required to densify the compact from an initial relative density $D_{0}$ to a relative density $D$ is given by

$$
P=\frac{\kappa \eta D Z_{0}}{\pi}\left(2 R_{1}\right)^{\frac{M-2}{2}}\left[1-\left(\frac{D_{0}}{D}\right)^{\frac{1}{3}}\right]^{\frac{2+M}{2}}\left(\frac{D_{0}}{D}\right)^{\frac{1}{3}}
$$




$$
\begin{gathered}
\kappa \equiv 1+\frac{2 C}{Z_{0}}\left(\frac{D}{D_{0}}\right)^{\frac{2}{3}}\left[1-\left(\frac{D_{0}}{D}\right)^{\frac{1}{3}}\right] \\
\times\left\{\frac{1}{4+M}-\frac{\left[1-\left(D_{0} / D\right)^{\frac{1}{3}}\right]}{6+M}\right\} \\
\eta=2^{-M} 3^{1-M} \pi c^{2+M} \sigma_{1} R_{1}^{\frac{2-M}{2}}
\end{gathered}
$$

and

$$
c=\sqrt{1.43} \exp [-0.485 M]
$$

The packing constants $\mathrm{Z}_{0}$ and $C$ take the values $\mathrm{Z}_{0}=7.3$ and $\mathrm{C}=15.5$ for dense random packing. Assuming infinitesimal straining and neglecting the formation of new contacts during compaction, equation (2) simplifies to

$$
P=\frac{\eta D_{0} Z_{0}}{\pi}\left(2 R_{1}\right)^{\frac{M-2}{2}}\left(\frac{D-D_{0}}{3 D_{0}}\right)^{\frac{2+M}{2}}
$$

Storakers et al. [15] show that the simplification (3) is in close agreement with (2) for the initial stages of densification $D-D_{0}<0.15$.

For the case of powder composites, the SFM theory assumes a bimodal distribution of spheres; one population is of radius $R_{1}$ and of strength $\sigma_{1}$, whereas the other population is of radius $R_{2}$ and of strength $\sigma_{2}$ (but with the same strain-hardening exponent $M$ ). The authors have used the statistics for each type of particle contact in a composite mixture as suggested by Turner [14], and calculated the macroscopic average stress as a function of macroscopic strain by assuming the affine motion of particles. When a composite mixture and the monolithic powder are subjected to the same strain history, they predict that the macroscopic stress in the composite is a factor of $K_{\mathrm{C}}$ times the macroscopic stress in the monolithic powder. The constraint factor $K_{\mathrm{C}}$ is defined by

$$
\begin{aligned}
K_{\mathrm{C}} & =\frac{D_{\mathrm{C}} Z_{\mathrm{C}}}{D_{0} Z_{0}} \frac{\left(f_{1}+f_{2} \rho^{2}\right)}{\left(f_{1}+f_{2} \rho^{3}\right)\left(f_{1}+f_{2} \rho\right)} \\
& \times\left[\frac{\left(f_{1}+f_{2} \rho\right)\left(f_{1}+f_{2} \rho^{2}\right)}{\left(f_{1}^{2}+2 f_{1} f_{2} \rho \gamma_{12}+f_{2}^{2} \rho^{2} \gamma_{22}\right)}\right]^{\frac{2+M}{2}}
\end{aligned}
$$

where $f_{1}$ and $f_{2}$ are the volume fractions of soft and hard particles, respectively, $\rho \equiv R_{2} / R_{1}$ is the ratio of particle sizes, $D_{\mathrm{C}}$ is the initial relative density of the composite, and $Z_{\mathrm{C}}$ is the average co-ordination number for the composite (taken as $Z_{\mathrm{C}}=12 D_{\mathrm{C}}$ ). The parameters $\gamma_{12}$ and $\gamma_{22}$ are specified by

$\dagger$ Air driven hydraulic pump (Model MS-71), $100 \mathrm{MPa}$ capacity, Haskel Energy Systems, UK.

$$
\gamma_{12}=\left[\frac{1+k^{-\frac{1}{M}}}{2}\right]^{\frac{2 M}{2+M}}\left(\frac{1+\rho}{2 \rho}\right)^{\frac{2-M}{2+M}}
$$

and

$$
\gamma_{22}=k^{\frac{-2}{2+M}} \rho^{\frac{M-2}{2+M}}
$$

in terms of the strength ratio $k \equiv \sigma_{2} / \sigma_{1}$.

\subsection{Scope of the present study}

In order to understand the effect of particle reinforcement on the densification and yield surface evolution of a metallic powder, triaxial experiments are reported herein for two types of powder composite: (i) lead shot and steel ball bearings, and (ii) gas atomised aluminium powder with silicon carbide reinforcement. Silicon carbide $(\mathrm{SiC})$ reinforced aluminium alloy composites are promising materials for powder metallurgy parts in the automotive industry. The $\mathrm{SiC}$ imparts high strength, stiffness and wear resistance, while the Al matrix provides adequate toughness and ductility.

In the following sections, a brief description of the triaxial apparatus is given and the experimental procedure is outlined. The effect of reinforcement on the isostatic and closed-die compaction response is explored, including the evolution of the yield surface. The focus is on Stage I compaction of composites, with plastic deformation concentrated at the contacts between particles, and porosity remaining inter-connected.

\section{TEST METHOD}

A high pressure triaxial system was used for compacting the composite powders and for subsequent probing of the yield surface, as sketched in Fig. 2. It consists of a pressure chamber, a thick walled cylinder, a base and a top cover. An axial force was applied to the specimen by a piston rod, and a hydraulic oil pump $\dagger$ applied hydrostatic pressure to the powder sample. The pressure chamber was designed to withstand a maximum pressure of 100 MPa. In order to apply an axial load to the specimen in addition to the hydrostatic pressure, the triaxial cell was mounted on the cross-head of a computer-controlled screw-driven Instron test machine (model number 6510) with an axial load capacity of $100 \mathrm{kN}$.

Circular cylindrical specimens of diameter $12.7 \mathrm{~mm}$ and length $25-30 \mathrm{~mm}$ were placed in an open-ended rubber tube, as sketched in Fig. 2. The volume fraction $f_{\mathrm{i}}$ of the inclusions relative to the total volume of solids was calculated from the following relation, 


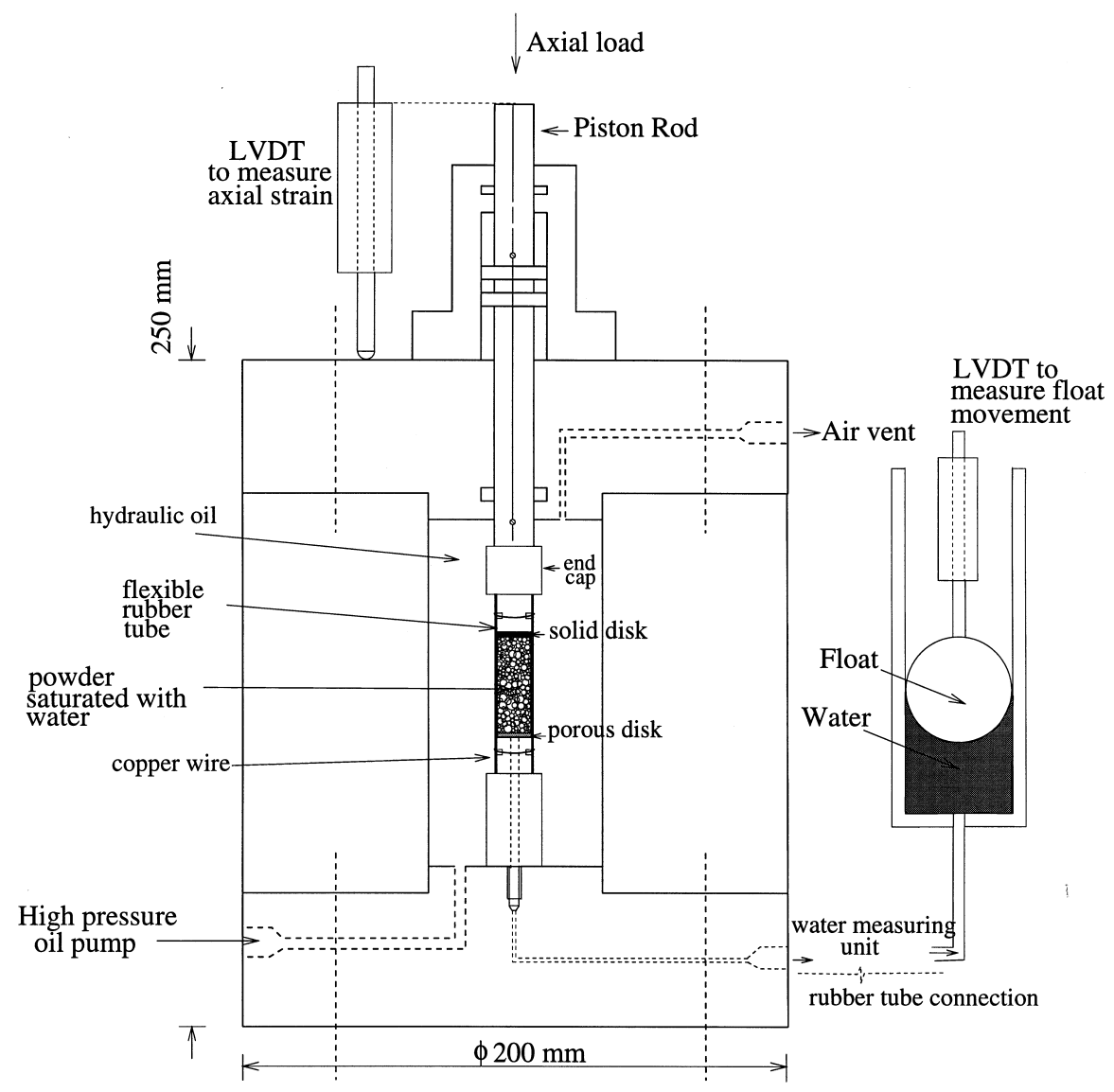

Fig. 2. Sketch of the triaxial pressure cell used for compacting cylindrical powder specimens, of diameter $12.7 \mathrm{~mm}$ and length $25-30 \mathrm{~mm}$, and for probing the yield surface.

$$
f_{\mathrm{i}}=\frac{\frac{m_{\mathrm{i}}}{\rho_{\mathrm{i}}}}{\frac{m_{\mathrm{i}}}{\rho_{\mathrm{i}}}+\frac{m_{\mathrm{m}}}{\rho_{\mathrm{m}}}}
$$

where $m_{\mathrm{i}}$ and $\rho_{\mathrm{i}}$ are the mass and density of the inclusions, and $m_{\mathrm{m}}$ and $\rho_{\mathrm{m}}$ are the mass and density of the matrix particles, respectively. The initial relative density $D_{0}$ of the powder mix was evaluated from the ratio of the actual volume of particles $\left(m_{\mathrm{m}} / \rho_{\mathrm{m}}+m_{\mathrm{i}} / \rho_{\mathrm{i}}\right)$ to the total volume.

A porous metal disc was located at the bottom of the specimen and the powder mix was saturated with water in order to monitor the pore volume. A solid steel disc was placed on the top surface of the specimen, and the two ends of the rubber tube were then tied to the end disks using copper wire of diameter $0.5 \mathrm{~mm}$. This arrangement prevented the penetration of oil into the specimen. The initial relative density of the powder sample was calculated from the initial length and diameter of the specimen, as measured by vernier calipers.

Axial loading was applied to the specimen via the

$\dagger$ Valimet, Inc., Stockton, California (USA). piston rod, and the axial displacement was measured using a linear voltage displacement transducer (LVDT) attached to the load cell. Compaction of the specimen forced water out from the pores through the lower porous disc to an external column of water. The volume of drained water was measured from the movement of a float placed in a water column with the aid of a second LVDT.

The axial force, axial displacement and the change in pore volume were monitored during the test using a computerised data logger; the relative density was thereby calculated from the volume and the mass of the specimen.

\subsection{Test materials}

The composite powders investigated were (i) aluminium and silicon carbide powders, and (ii) lead shot and steel balls. Representative micrographs of the constituent powders are given in Fig. 3.

The aluminium (Al) powder used is a $\mathrm{H}-5$ research grade $(99.6 \mathrm{wt} \% \mathrm{Al}, 0.2 \mathrm{wt} \%$ oil and grease, $0.2 \mathrm{wt} \% \mathrm{Fe}$ ) produced by argon atomisation $\dagger$. This $\mathrm{Al}$ powder is nearly spherical in shape with many satellite sub-particles and has an ap- 


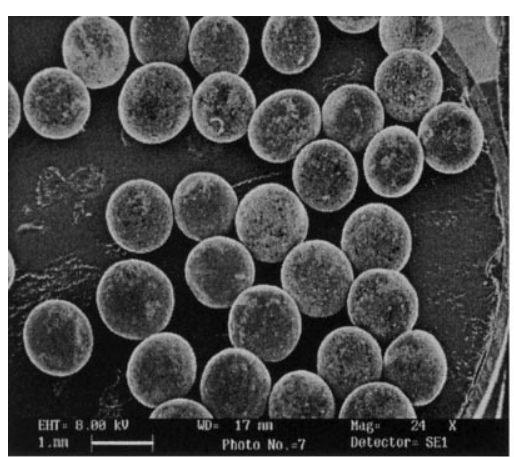

(a) Lead Shot

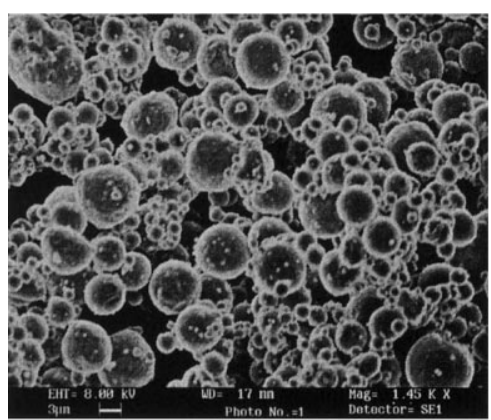

(c) Aluminium $\longmapsto$

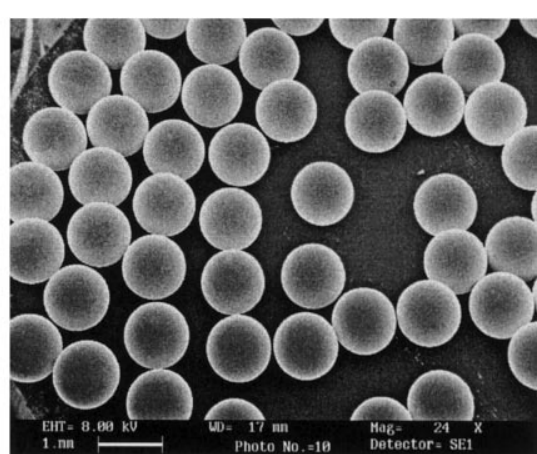

(b) High Strength Steel Balls
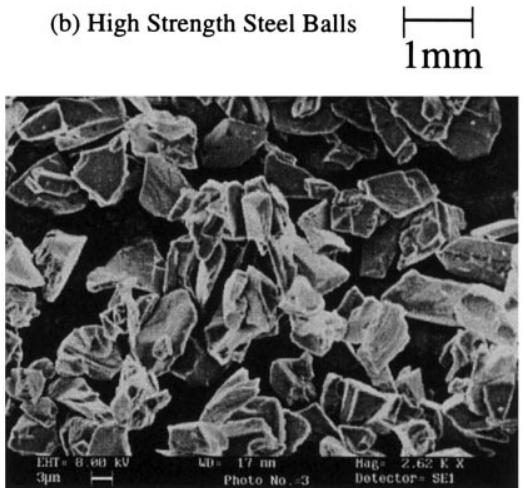

(d) Silicon Carbide

$$
\stackrel{\vdash}{10 \mu \mathrm{m}}
$$

Fig. 3. Micrographs of lead shot, steel balls, aluminium and silicon carbide particles used in the compaction experiments. The lead shot, steel balls and aluminium are spherical in shape, whereas the silicon carbide has an irregular morphology.

proximate particle size distribution (Fisher index) of 4.5-7 $\mu \mathrm{m}$. The uniaxial true stress $\sigma$ vs logarithmic strain $\epsilon$ behaviour of pure annealed aluminium can be represented by $\sigma=146 \epsilon^{0.24} \mathrm{MPa}$ [16], and the bulk density of aluminium is $2700 \mathrm{~kg} / \mathrm{m}^{3}$. The silicon carbide $(\mathrm{SiC})$ particles $\dagger$ possess an irregular, angular morphology, with a mean length of $10 \mu \mathrm{m}$ and a solid density of $3200 \mathrm{~kg} / \mathrm{m}^{3}$. The Young's modulus of $\mathrm{SiC}$ is about $450 \mathrm{GPa}$ [17]. The irregularity in shape of these particles produces some interlocking during compaction, and consequently the $\mathrm{Al}-\mathrm{SiC}$ compact can be handled without damage after compaction.

Tests were also performed on model materials consisting of $20 \%$ and $40 \%$ volume fraction steel ball bearings mixed with lead shot. Three different diameters $(1.5,1.0$ and $0.5 \mathrm{~mm})$ of $\mathrm{G} 100$ carbon grade chrome steel balls were used; $\$$ thereby, the effect of the relative size of reinforcement to the deformable phase upon the compaction behaviour was studied. The chemical composition of the steel balls is $0.98-1.10 \% \mathrm{C}, 1.3-1.6 \% \mathrm{Cr}, 0.25-0.45 \%$

$\dagger$ Exolon-ESK, Tonawanda, New York (USA). $\$$ Atlas Ball and Bearing Co. Ltd, Walsall (UK). $\S$ Calder Industrial Materials Ltd, Chester (UK).
$\mathrm{Mn}, 0.15-0.35 \% \mathrm{Si}, 0.025 \% \mathrm{~S}$ and $0.025 \% \mathrm{P}$ (all $\mathrm{wt} \%$ ). The steel balls have a bulk density of 7800 $\mathrm{kg} / \mathrm{m}^{3}$, Young's modulus of $203 \mathrm{GPa}, 0.1 \%$ offset yield strength of $2035 \mathrm{MPa}$, tensile strength of 2240 $\mathrm{MPa}$, and a tensile ductility of $5 \%$.

The lead shot $\S$ is a soft temper spherical powder, with a wide distribution of diameter $0.5-1.5 \mathrm{~mm}$, and a rough as-cast surface finish. The deviation in diameter from spherical is less than $10 \%$. The size distribution of lead shot was reduced by mechanical sieving: lead shot of diameter in the narrow ranges of $1.0-1.18 \mathrm{~mm}$ and $0.71-0.8 \mathrm{~mm}$ were used. The bulk density of the lead shot is $11,100 \mathrm{~kg} / \mathrm{m}^{3}$, and the micro Vickers hardness was found to be 8.9 $\mathrm{MPa}$. The uniaxial stress-strain response of the lead shot can be represented by $\sigma=15 \epsilon^{0.21} \mathrm{MPa}$ [18], where $\sigma$ is true stress, and $\epsilon$ is logarithmic plastic strain.

\subsection{Yield surface measurement}

The loading state on the specimen is summarised in Fig. 1(a). Each specimen was subjected to a confining pressure $P$ and an additional (compressive) axial stress $\sigma$, with the principal stresses $\left(\Sigma_{11}, \Sigma_{22}\right.$, $\left.\Sigma_{33}\right)$ given by 


$$
\begin{aligned}
& \Sigma_{11}=\Sigma_{22}=-P \\
& \Sigma_{33}=-(P+\sigma)
\end{aligned}
$$

The corresponding mean stress $\Sigma_{\mathrm{m}}$ and deviatoric stress $\Sigma$ are defined by

$$
\begin{gathered}
\Sigma_{\mathrm{m}}=\frac{1}{3}\left(\Sigma_{11}+\Sigma_{22}+\Sigma_{33}\right)=-\left(P+\frac{\sigma}{3}\right) \\
\Sigma=\Sigma_{33}-\Sigma_{11}=-\sigma
\end{gathered}
$$

In the hydrostatic compaction tests, the confining pressure was increased incrementally and the corresponding change in volume of the specimen was recorded. After the required relative density had been attained, the yield surface was probed as follows: the specimen was unloaded hydrostatically by decreasing the hydrostatic pressure to a fixed value within the yield surface, and was then held constant. The axial load was incremented until the specimen yielded. A plot of axial load against axial displacement on an $X-Y$ recorder was used to determine the onset of yielding; the axial plastic strain accumulated during each probing operation was less than 0.01. After reactivation of yield, the specimen was unloaded axially, and the pressure was reduced to a new value; the probing process was then repeated.

The strain path in a closed-die compaction was simulated using the triaxial cell, without the added complication of die wall friction. Hydrostatic pressure and axial load were applied in small increments such that the accumulated volumetric strain and axial strain were equal; this process was repeated until the required relative density was attained.

The probing of the yield surface after closed-die compaction was carried out by two types of test in order to probe as much of the yield surface as possible. The first method was similar to the one used for hydrostatic compaction: after some hydrostatic unloading, the confining pressure was kept constant and the axial load was incremented until yield occurred. This procedure was then repeated. The second procedure also began from the loading point associated with a finite amount of closed-die compaction. The specimen was relaxed from the loading point by movement of the cross-head at fixed confining pressure $P$. Then, the cross-head was held fixed and $P$ was increased until yield was re-activated. (A plot of $P$ vs hydrostatic strain was used to determine the onset of yield.) The yield surface was mapped by repeating this procedure. Care was taken to ensure that the change in relative density $D$ was less than $0.05 \%$ each time yield was re-activated.

\section{RESULTS AND DISCUSSION}

In this section, experimental results are presented (a)

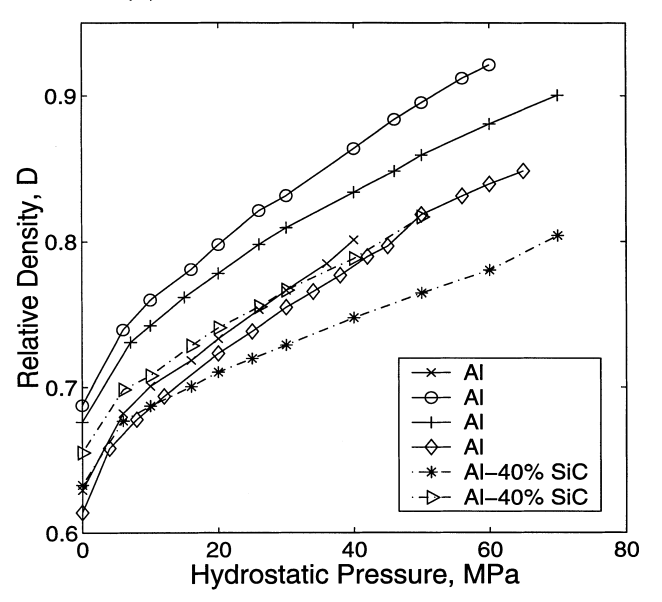

(b)

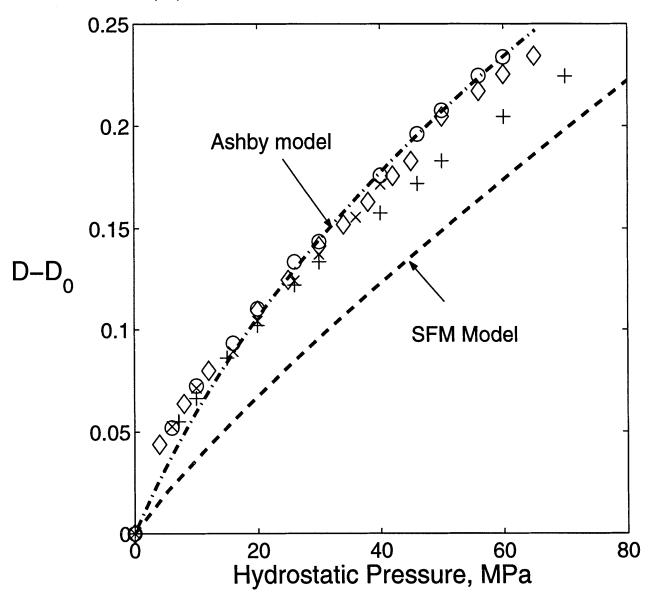

(c)

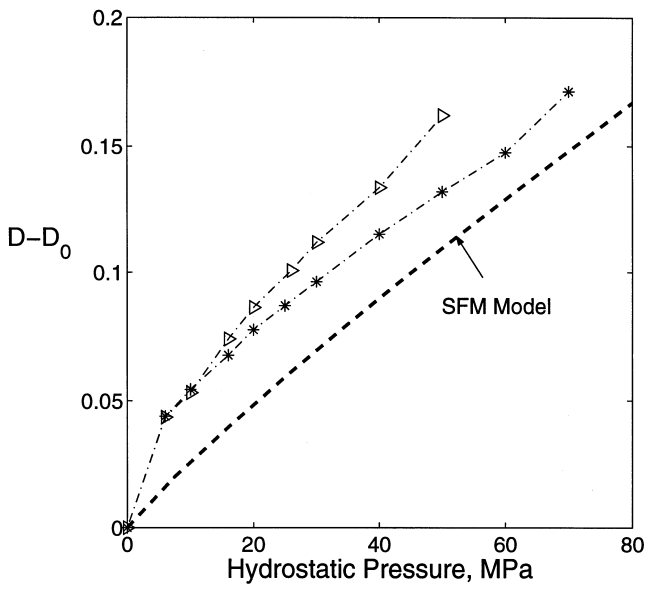

Fig. 4. (a) Measured relative density $D$ vs hydrostatic pressure $P$ of aluminium and $\mathrm{Al}-40 \% \mathrm{SiC}$ composite. (b) The densification data for Al are compared with Ashby's model equation (1) and with the SFM model, equation (2). (c) The densification data for $\mathrm{Al}-40 \% \mathrm{SiC}$ are compared with the SFM model. 
for the triaxial tests conducted on $\mathrm{Al}$ and $\mathrm{SiC}$ mixtures, and the lead-steel composites. Aluminium and the $\mathrm{Al}-\mathrm{SiC}$ mixtures were subjected to both isostatic and closed-die compaction, whereas the lead shot-steel composites were subjected only to isostatic compaction. After the initial compaction, the yield surface was probed in axisymmetric stress space.

\subsection{Isostatic compaction of $\mathrm{Al}$ and $\mathrm{Al}-40 \% \mathrm{SiC}$ composite}

Consider first the isostatic compaction response of $\mathrm{Al}$ powder, and $\mathrm{Al}$ powder reinforced by 40 vol. \% SiC. Figure 4(a) shows the measured densification response (relative density $D$ vs hydrostatic pressure $P$ ) for isostatic compaction of the aluminium powder. There is a monotonic increase in relative density with pressure. Note that the initial relative density $D_{0}$ varied from specimen to specimen due to slight variations in the initial packing and in the particle size distribution. The isostatic densification response of aluminium powder reinforced with 40 vol. \% SiC particles is included in Fig. 4(a). Greater pressures are required for the compaction of $\mathrm{Al}-\mathrm{SiC}$ composite compared with that for the aluminium powder. For example, for the case of an initial relative density $D_{0}$ of 0.63 , the pressure required to densify the $\mathrm{Al}-40 \% \mathrm{SiC}$ composite to $D=0.80$ was 1.75 times that for the aluminium powder. This compares with a constraint ratio of 3 for $40 \%$ steel balls and aluminium powder, as reported by Lange et al. [13].

In Fig. 4(b), the observed hydrostatic compaction of the aluminium powder is compared with Ashby's prediction [6], as stated in equation (1) and with the SFM theory, as given in equation (2). In the evaluation of equation (1), an initial relative density $D_{0}=0.64$ was used and the uniaxial yield strength $\sigma_{\mathrm{y}}$ of solid aluminium was taken as $40 \mathrm{MPa}$ [17]. Ashby's model adequately captures the observed response of the aluminium powder. The SFM model (with $D_{0}=0.64$ and $Z_{0}=7.3$ ) predicts a stiffer response than the measured values, possibly for the following reasons. The SFM model assumes a kinematically admissible field, based on the affine motion of particle centres without rotation; thus, the effects of particle rearrangement in the initial stages of compaction are neglected, and the model is an upper bound to the true response. Further, recent calculations by Mesarovic and Fleck [20] reveal that the local indentation response between particles (both soft-soft and soft-hard contacts) is less stiff than the contact laws assumed by Storakers et al. [15] by $30-40 \%$. Thus the predicted macroscopic stresses for compaction are expected to be at least $30-40 \%$ less than that given by the original SFM model.

The densification response of $\mathrm{Al}-40 \% \mathrm{SiC}$ has also been compared with the composite powder compaction theory of Storakers et al. [15] in Fig. 4(c). For the predictions, the SiC particles are treated as rigid, the initial density of composite $D_{\mathrm{C}}$ is taken as the measured value and $Z_{\mathrm{C}}=12 D_{\mathrm{C}}$ as suggested by Storakers et al. [15]. The SFM theory also predicts a stiffer response than the observed behaviour; the reasons for the discrepancy are thought to be the same as given above for the monolithic case.

3.1.1. Isostatic yield surface of $\mathrm{Al}$ and $\mathrm{Al}-$ $40 \% \mathrm{SiC}$. The yield surface of the isostatically compacted aluminium specimens was probed for values of $D$ in the range $0.80-0.82$. The measured yield data are plotted in Fig. 5(a) using axes of mean stress $\Sigma_{m}$ and deviatoric stress $\Sigma$. We note that the yield surfaces are geometrically self-similar, but increase in size with increasing densification $\Delta D \equiv D-D_{0} ;$ compacted specimens lose their

(a)
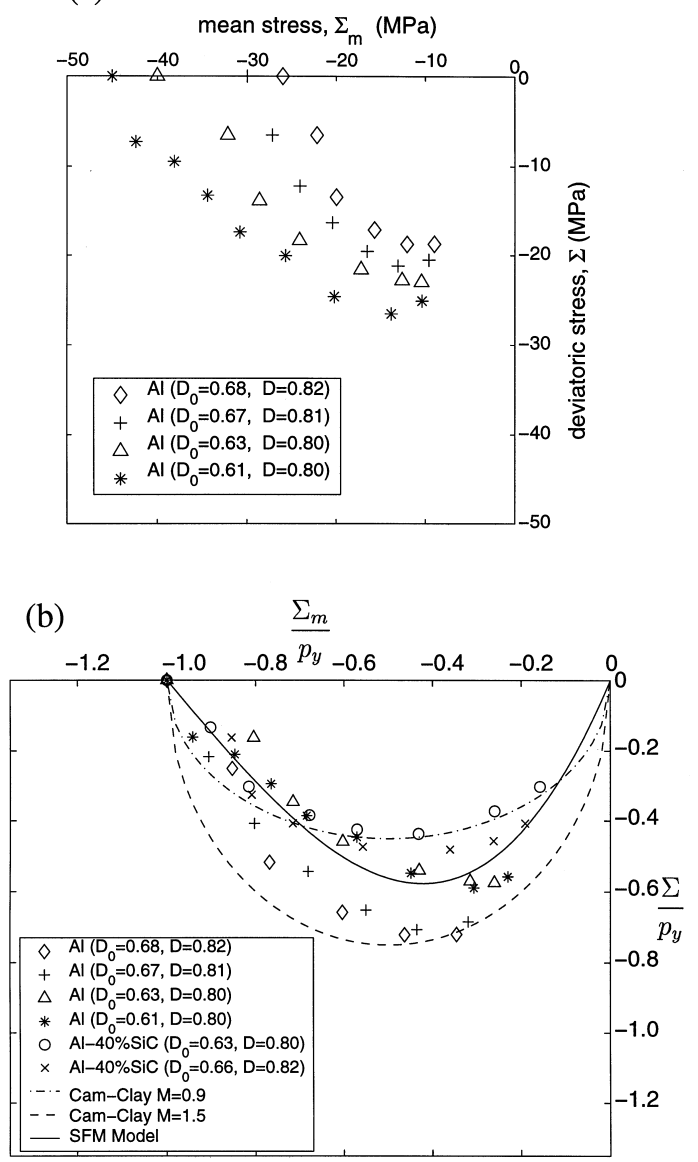

Fig. 5. (a) Yield surface of aluminium powder after hydrostatic compaction. (b) Comparison of the measured yield surfaces for $\mathrm{Al}$ and $\mathrm{Al}-40 \% \mathrm{SiC}$ with the predictions of Storakers et al. [15] and the modified Cam-Clay model in mean stress vs deviatoric stress space. The stresses have been normalised by the measured and predicted hydrostatic strength, $p_{\mathrm{y}}$. 
deviatoric strength under zero confining pressure. The yield surfaces are replotted in Fig. 5(b) after normalising by the hydrostatic pressure $p_{\mathrm{y}}$ required to compact the specimens to the given relative density. The yield surface for isostatic compaction of $\mathrm{Al}-\mathrm{SiC}$ composite has been normalised in the same manner, and the results are included in Fig. 5(b). To within material scatter, the yield surface for the $\mathrm{Al}-\mathrm{SiC}$ composite aligns with that for the Al powder. A trend in the data for both the aluminium and the composite is observed from Fig. 5(b): the peak normalised deviatoric strength increases with increasing initial relative density $D_{0}$. It is speculated that a low value of $D_{0}$ allows for greater particle rearrangement during the initial stages of compaction and to a reduced deviatoric strength.

It is instructive to compare these measurements with the predictions of the SFM model [15] and the modified Cam-Clay model [19]. The isostatic yield surface proposed by the SFM model [15] for powders of zero cohesion and $M=0$ is given by

$$
\begin{aligned}
\phi\left(\Sigma_{\mathrm{m}}, \Sigma\right) & =\frac{\Sigma}{p_{\mathrm{y}}}+\frac{3}{2} \frac{\Sigma_{\mathrm{m}}}{p_{\mathrm{y}}}\left[1-\left(\frac{\Sigma_{\mathrm{m}}}{p_{\mathrm{y}}}\right)^{2}\right]=0, \\
\text { for } \Sigma & >0
\end{aligned}
$$

and

$$
\begin{aligned}
& \phi\left(\Sigma_{\mathrm{m}}, \Sigma\right) \\
& =\frac{\Sigma}{p_{\mathrm{y}}}+\frac{3}{2} \frac{\Sigma_{\mathrm{m}}}{\sigma_{\mathrm{y}}}\left(1+\frac{\Sigma_{\mathrm{m}}}{p_{\mathrm{y}}}\right)\left(2+\frac{\Sigma_{\mathrm{m}}}{p_{\mathrm{y}}}\right)=0, \\
& \text { for } \quad \Sigma<0
\end{aligned}
$$

The yield surface (8-9) was first derived by Fleck [10] for the isostatic limit, and it bears some resemblance to the modified Cam-Clay model [19],

$$
\phi_{\mathrm{c}}\left(\Sigma_{\mathrm{m}}, \Sigma\right)=\frac{\Sigma_{\mathrm{m}}}{p_{\mathrm{y}}}\left(\frac{\Sigma_{\mathrm{m}}}{p_{\mathrm{y}}}-1\right)+\left(\frac{\Sigma}{M p_{\mathrm{y}}}\right)^{2}=0
$$

where $M$ is an adjustable parameter controlling the ellipticity of the yield surface and $p_{\mathrm{y}}$ is the hydrostatic yield pressure. The modified Cam-Clay model is elliptical in shape, is symmetric about the hydrostatic axis, and passes through the origin of stress space for the case of zero cohesive strength.

For comparison purposes, the SFM yield surface and the modified Cam-Clay model are included in Fig. 5(b). For both the aluminium powder and the composite, the SFM model and the Cam-Clay model (with $0.9 \leq M \leq 1.5$ ) are in reasonable agreement with the data. In particular, specimens with low initial relative density $\left(D_{0}<0.64\right)$ have a measured yield surface in support of the SFM theory. (a)

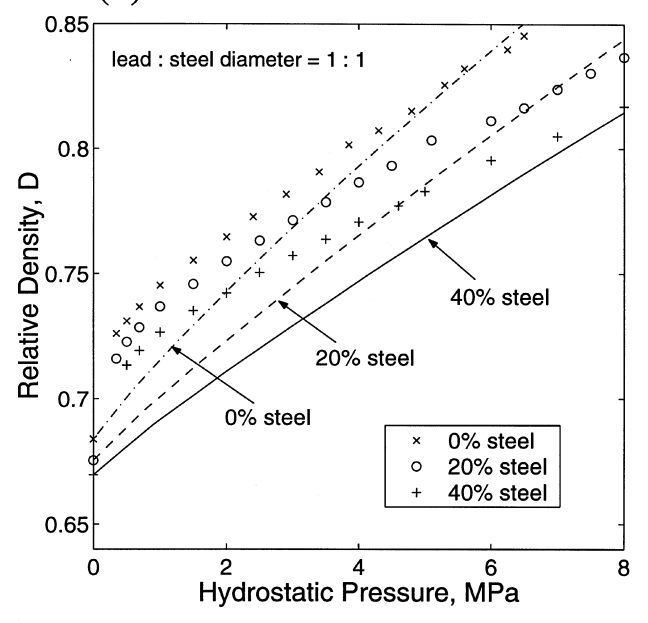

(b)

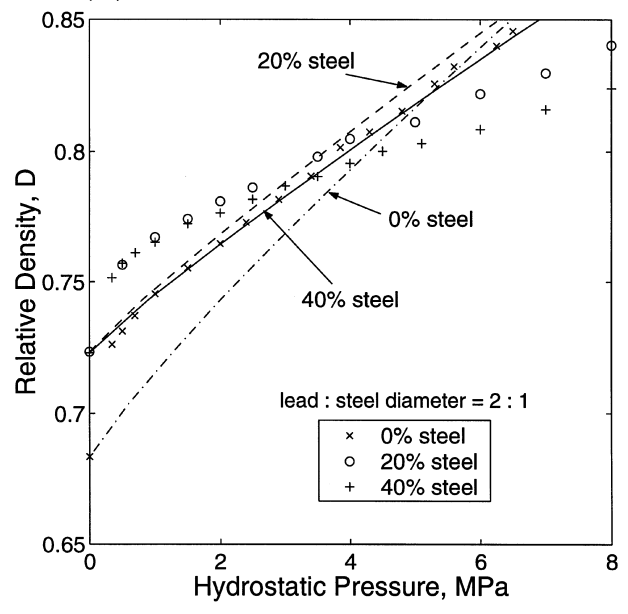

(c)

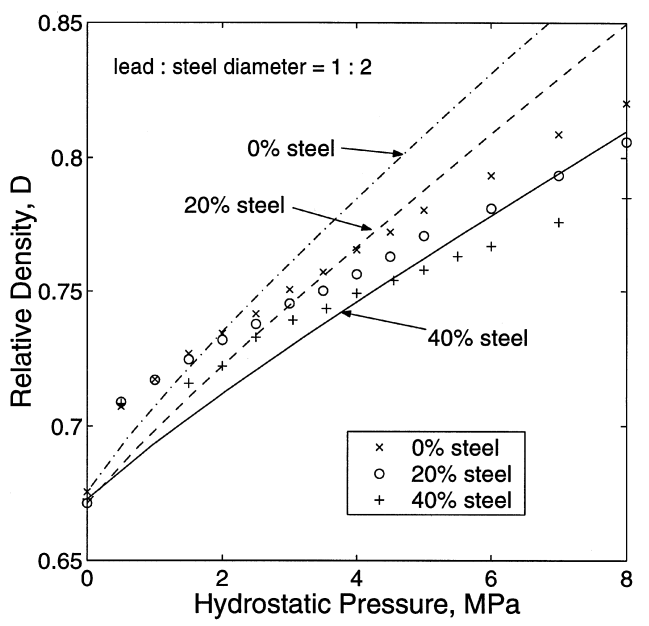

Fig. 6. Effect of volume fraction of steel ball bearings upon the isostatic compaction of lead shot. (a) Steel diameter $=1 \mathrm{~mm}$, lead shot diameter $=1.0-1.2 \mathrm{~mm}$; (b) steel diameter $=0.5 \mathrm{~mm}$, lead shot diameter $=1.0-1.2 \mathrm{~mm}$; (c) steel diameter $=1.5 \mathrm{~mm}$, lead shot diameter $=0.7$ $0.8 \mathrm{~mm}$. The lines are the predictions of the SFM model [15]. 


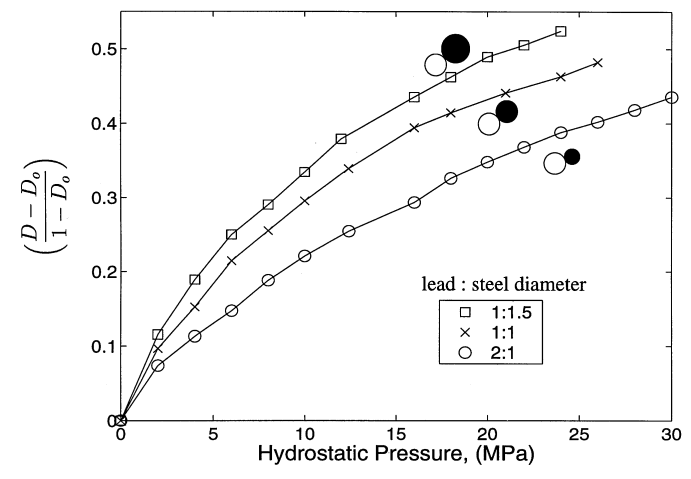

Fig. 7. Effect of size ratio of steel ball bearings to lead shot upon the isostatic compaction response, for $40 \%$ volume fraction of steel reinforcement.

\subsection{Isostatic compaction of lead shot-steel composite}

Lead shot-steel composites were compacted isostatically, and the subsequent yield surfaces were probed, as follows. The size ratio (i.e. diameter ratio) of lead shot to the steel balls was taken as $1: 1,2: 1$ and $1: 2$, and the relative volume fraction of steel balls was $0 \%, 20 \%$ and $40 \%$. The pressure $P$ vs relative density $D$ compaction response is shown in Figs 6(a)-(c) for the size ratios 1:1, 2:1 and 1:2, respectively (details on particle size are given in the figure caption). When the size ratio is $1: 1$, or $1: 2$ the initial relative density $D_{0}$ is 0.67 , as seen in Figs 6(a) and (c). In contrast $D_{0}$ equals approximately 0.72 when the steel ball diameter is half that of the lead shot, see Fig. 6(b); this greater packing density is due to the fact that the smaller inclusions partially fill the space between the larger lead particles.

The pressure required to attain a given relative density increases with increasing volume fraction of steel ball reinforcement, for all size ratios. The increased macroscopic strength with increasing fraction of steel ball reinforcement is thought to be associated with the increasing probability of elastic contacts between touching steel balls, as discussed by Storakers et al. [15] and by Bouvard and Lange [21].

The experimental measurements are compared with the theory of Storakers et al. [15] in Figs 6(ac). For the predictions, we take the initial density $D_{0}$ of the lead particles and $D_{\mathrm{C}}$ of the composite as the measured values, and assume $Z_{0}=7.3$ and $Z_{\mathrm{C}}=12 D_{\mathrm{C}}$, following [15]. Note that the theoretical results are valid only for Stage I compaction, such that $D \leq 0.8$. When the size ratio of lead shot to steel balls is $1: 1$, the predicted compaction pressures somewhat exceed the observed values for $D<0.8$. At other size ratios (1:2 and 2:1) the predicted pressures exceed the measured values at the beginning of Stage I compaction, but drop below the measured values later in the compaction history. The experimental scatter in the compaction tests [also evidenced for $\mathrm{Al}$ and $\mathrm{Al}-\mathrm{SiC}$ in Figs 4(a) and 4(c)] make it difficult to comment upon the accuracy of the theory, and where any deficiencies arise.

A repeat isostatic test was conducted on 1.00 $1.18 \mathrm{~mm}$ diameter lead shot in order to assess the effects of creep upon the compaction response. First, the sample was compacted isostatically from $D_{0}=0.65$ to $D=0.807$ at the usual rate $\left(\dot{D}=1.3 \times 10^{-4} / \mathrm{s}\right)$; this stage of the test took about 1200 s. Second, the final pressure was maintained over an additional $7200 \mathrm{~s}$ : the relative density increased by about $1 \%$ to $D=0.815$. We conclude that the contribution of creep to the original densification is negligible. In each of the tests conducted in the present study, it was ensured that the test time was less than $7200 \mathrm{~s}$.

The effect of particle size ratio $\rho$ upon the iso-

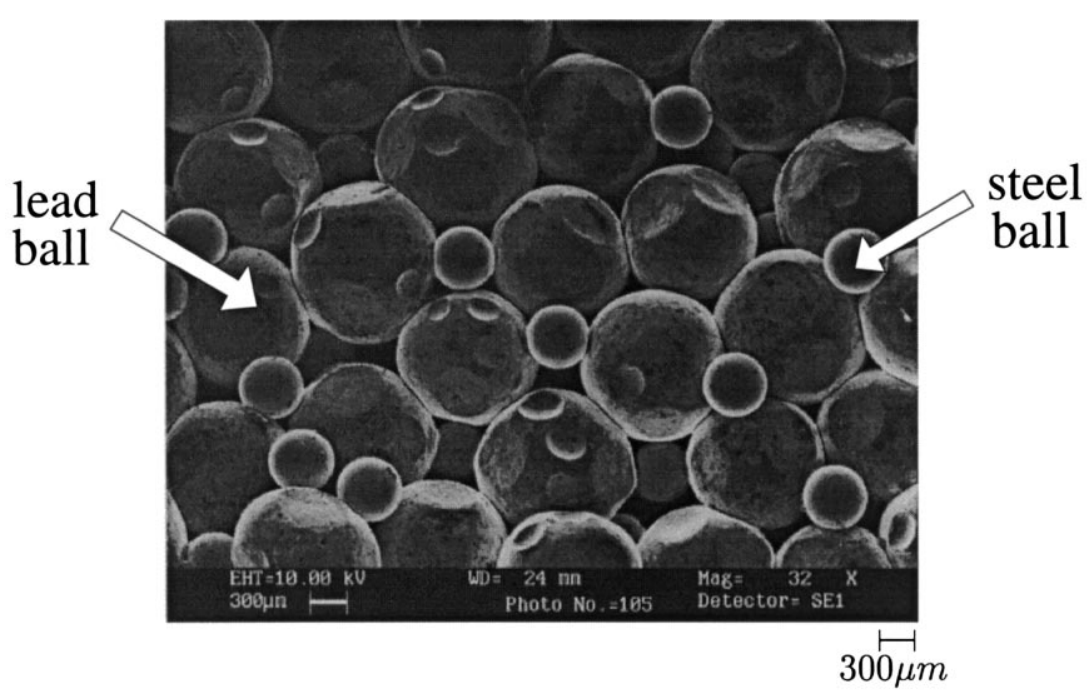

Fig. 8. SEM micrograph of isostatically compacted specimens containing $20 \%$ volume fraction steel ball bearings, of diameter half that of the lead shot $D_{0}=0.72, D=0.92$. 
static compaction response is shown in Fig. 7, for the case of lead shot of diameter $1.00-1.18 \mathrm{~mm}$, reinforced by $40 \mathrm{vol} \%$ fraction of steel balls. It is found that the strength of the steel/lead mixture increases with diminishing relative size of steel ball to lead shot. These enhancements in strength are in agreement with the cold isostatic compaction measurements of Turner [14].

Typically, specimens disintegrated into discrete particles upon removal from the rubber tube after the compaction test: this is due to the absence of adhesion between the powder particles. Occasional intact regions of the specimens exist, and these were examined in a scanning electron microscope (SEM); a typical micrograph is shown in Fig. 8 for the case of $20 \mathrm{vol.} \%$ fraction of steel balls, of diameter half that of the lead shot. The facets on the lead spheres arise from the mutual indentation of lead-lead and lead-steel balls during compaction. No visible deformation is evident on the steel balls: elastic indentation only occurred during compaction.

The effect of size ratio upon the isostatic yield surface for lead shot-steel composite is shown in Figs 9 (a)-(c) for $D \approx 0.8$. The mean and deviatoric stress components have been normalised by the measured compaction pressure, $p_{\mathrm{y}}$. The experimental data are compared with the modified Cam-Clay model with $M=0.7$ and with the prediction of SFM model [15]. It is noted from Figs 9(a)-(c) that the maximum value of normalised shear strength $\left|\Sigma / p_{\mathrm{y}}\right|$ is approximately 0.4 for the lead shot and for the various lead-steel composites, whereas the SFM model predicts a value of 0.6. The reasons for the low shear strength of lead shot requires further investigation. There appears to be no consistent effect of the volume fraction or relative size of reinforcement upon the yield surface shape, to within experimental scatter.

\subsection{Closed-die compaction of $\mathrm{Al}-40 \% \mathrm{SiC}$}

The densification response during closed-die compaction is shown in Fig. 10(a) for $\mathrm{Al}$ and for $\mathrm{Al}-$ $40 \% \mathrm{SiC}$. In both cases the measured axial stress is three to four times the radial stress during compaction. This finding is in agreement with the available experimental values for the Stage I compaction of aluminium, iron and copper, where $\Sigma_{33} / \Sigma_{11}=1.5-$ 5.5 (as reviewed by Fleck [10]). This lends some support to the compaction model of Storakers et al. [15]: for a rigid, ideally plastic composite they find $\Sigma_{33} / \Sigma_{11}=3$ for Stage I compaction.

The measured yield surfaces after closed-die compaction of $\mathrm{Al}$ powder and $\mathrm{Al}-40 \% \mathrm{SiC}$ (vol.) composite are shown in Fig. 10(b), for a relative density $D=0.8$. The addition of $40 \% \mathrm{SiC}$ reinforcement enlarges the yield surface but does not change its shape. On comparing Fig. 5(b) with Fig. 10(b), we conclude that the shape of the yield surface after
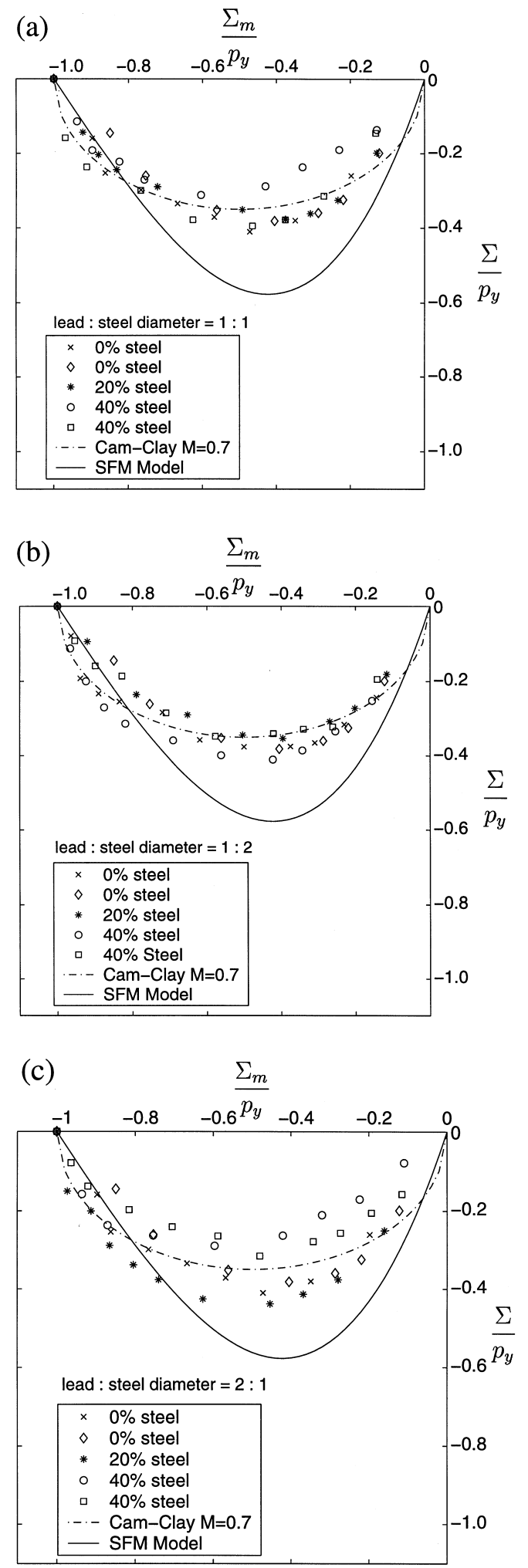

Fig. 9. Measured yield surface of hydrostatically compacted lead shot and steel balls of volume fraction of steel $=0 \%, 20 \%$ and $40 \%$. The data are compared with SFM model [15] and the modified Cam-Clay model with $M=0.7$. Size ratio of lead shot:steel balls equals (a) $1: 1$, (b) $1: 2$ and (c) $2: 1$. 
(a)

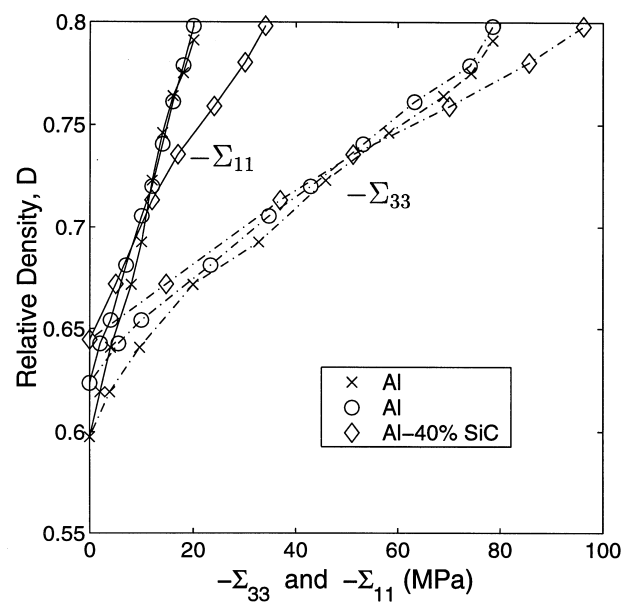

(b)

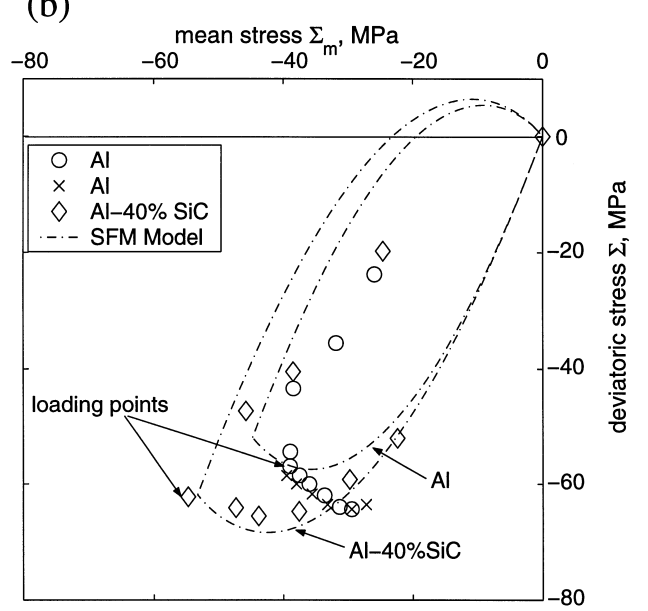

Fig. 10. (a) Macroscopic axial $\left(\Sigma_{33}\right)$ and radial $\left(\Sigma_{11}\right)$ stresses vs relative density during closed-die compaction of $\mathrm{Al}$ and $\mathrm{Al}-40 \% \mathrm{SiC}$ composite. (b) Measured yield surface after closed-die compaction of $\mathrm{Al}$ and $\mathrm{Al}-40 \% \mathrm{SiC}$ composite at a relative density $D=0.8$. Predictions of the Storakers, Fleck and McMeeking (SFM) model [15] are included.

closed-die compaction is strikingly different from that due to isostatic compaction. The closed-die yield surface is elongated with a corner at the loading point. A similar observation for copper powder was made by Akisanya and co-workers [11].

The predicted yield surfaces [15] due to closed-die compaction of a rigid, ideally plastic powder with and without $40 \%$ reinforcement by $\mathrm{SiC}$ inclusions are included in Fig. 10(b). The material strength of $\mathrm{Al}$ in the model has been chosen so that the macroscopic deviatoric strength $\Sigma$ of the model for the $\mathrm{Al}-\mathrm{SiC}$ equals the measured value at the loading point, for $D=0.8$. According to the model, closeddie compaction gives larger contacts along the axial direction than along other directions [10] and so the yield surface is elongated along the direction of initial loading and is contracted in the transverse direction. The model of Storakers et al. [15] appears to be satisfactory in capturing the size and shape of yield surface for the $\mathrm{Al}$ and $\mathrm{Al}-\mathrm{SiC}$ compacts. According to this model, the yield surface of a powder composite enlarges by the scale factor $\left(1-f^{2}\right)^{-1}$ upon introduction of a volume fraction $f$ of rigid reinforcement.

\section{CONCLUDING REMARKS}

A triaxial pressure cell was used to obtain the pressure vs relative density response of cold compacted powders: the pressure required to compact a powder composite increases with increasing volume fraction of reinforcement phase (steel balls or $\mathrm{SiC}$ grit) in a matrix of deformable particles (aluminium or lead shot).

The observed yield surface of isostatically compacted powder composites can be represented by an ellipse in mean stress vs effective stress space. Closed-die compaction results in a yield surface which is elongated along the direction of initial straining. Strong anisotropy develops and it is thought that this is a result of orientation-dependent contact growth between particles.

The presence of reinforcing inclusions strengthens a powder compact and thereby enlarges the yield surface, but does not change the shape of the yield surface, for both isostatic and closed-die straining paths.

Acknowledgements - The authors are grateful for financial support from NIST, under contract 70-NANB5H0042 and to Dr Richard J. Fields for providing aluminium and silicon carbide powders. IS thanks Cambridge Commonwealth Trust for funding in the form of a research studentship. The authors also wish to thank Professor K. S. Kim of Brown University and Dr A. R. Akisanya of Aberdeen University for practical advice.

\section{REFERENCES}

1. Doraivelu, S. M., Gegel, H. L., Gunasekhara, J. S., Malas, J. C. and Morgan, J. T., Int. J. Mech. Sci., 1984, 26, 527

2. Kuhn, H. A. and Downey, C. L., Int. J. Powder metall., 1971, 7, 15 .

3. Kim, K. T., Suh, J. and Kwon, Y. S., Powder metall., 1990, 33(4), 321.

4. Brown, B. S. and Abou-Chedid, G., J. Mech. Phys Solids, 1994, 42, 383.

5. Arzt, E., Acta metall., 1992, 30, 1881

6. Ashby, M. F., HIP 6.0 Background Reading, The modelling of hot-isostatic pressing. Cambridge University Engineering Department Report, Cambridge, 1990.

7. Fischmeister, H. F. and Arzt, E., Powder metall., 1983, 26, 82.

8. Helle, H. S., Easterling, K. E. and Ashby, M. F., Acta metall., 1985, 33, 2163.

9. Fleck, N. A., Kuhn, L. T. and McMeeking, R. M., $J$ Mech. Phys. Solids, 1992, 40, 1139.

10. Fleck, N. A., J. Mech. Phys. Solids, 1995, 43, 1409.

11. Akisanya, A. R., Cocks, A. C. F. and Fleck, N. A., Int. J. Mech. Sci., 1997, 39, 1315. 
12. Larsson, P. L., Biwa, S. and Storakers, S., Acta mater., 1996, 44, 3655.

13. Lange, F. F., Atteraas, F., Zok, F. and Porter, J. R., Acta metall. mater., 1991, 39, 209.

14. Turner, C. D., Fundamental investigations of the isostatic pressing of composite powders. Ph.D. Dissertation, Cambridge University Engineering Department, 1994.

15. Storakers, B., Fleck, N. A. and McMeeking, R. M., J. Mech. Phys. Solids, 1999, 47(4), 785.

16. Boyer, H. E. (ed.), Atlas of Stress-Strain Curves. ASM International, Metals Park, OH, 1987, p. 390.
17. Ashby, M. F. and Jones, D. R. H., Engineering Materials I: An Introduction to Their Properties and Applications. Pergamon Press, Oxford, 1989.

18. Akisanya, A. R. and Fleck, N. A., Acta metall. mater., 1993, 41, 121.

19. Wood, D. M., Soil Behaviour and Critical State Soil Mechanics. Cambridge University Press, Cambridge, 1990.

20. Mesarovic, S. D. and Fleck, N. A., Int. J. Solids Structures, in press.

21. Bouvard, D. and Lange, F. F., Acta metall. mater., 1991, 39, 3083. 